\title{
Three-phase Planar Actuator's Reduced Model Validation Using Exploratory Coils and Evaluation Applying Somaloy500 as Core Material
}

\author{
Neto, J. M. ${ }^{1}$, Sebastião, L.M ${ }^{1}$, Spacek, A. D. ${ }^{1}$, Ferreira, A. C ${ }^{1}$, Ando Junior, O. H. ${ }^{2}$, Schaeffer, L. ${ }^{3}$ \\ ${ }^{1}$ Department of Industrial Automation \\ SATC, Beneficent Association of Santa Catarina Coal Industry \\ Street Pascoal Meller, 73. Criciúma-Sc (Brazil) \\ Phone/Fax number: +5548 34317568, e-mail: joao.neto@satc.edu.br;anderson.spacek@satc.edu.br \\ ${ }^{2}$ Department of Renewable Energies Engineering \\ UNILA, Federal University of Latin American Integration \\ Av. Sílvio Américo Sasdelli, 1842. Foz do Iguaçu, PR (Brazil) \\ Phone/Fax number: +55 45 35292832, e-mail: oswaldo.junior@unila.edu.br \\ ${ }^{3}$ School of Engineering \\ UFRGS, Federal University of Rio Grande do Sul \\ Av. Osvaldo Aranha, 103. Porto Alegre-Rs (Brazil) \\ Phone/Fax number: +55 51 3308-31.29, e-mail: schaefer@ufrgs.br;malfatti@ufrgs.br
}

\begin{abstract}
This article applies the Three-phase Planar Actuator (T.P.A.) core in two configurations: complete and reduced model for analysis in numerical and real modes. The T.P.A. is a two degree of freedom induction machine similar as two linear motors in a unique traction element. To validate the simulations, a real T.P.A. was built with Steel1010 as core material. The magnetic flux was measured by exploratory coils and compared with numerical model software's results. After the validation, the core's material was substituted by SMC Somaloy500 which has a high magnetic permeability allied with a higher resistivity than Steel1010 - and new simulations were made with variation of operating frequencies. The validation's results indicate a correct numerical modelled device with a maximum error of $9,64 \%$ and a better response with SMC Somaloy500 for force measurements - especially in relative high frequencies up to $120 \mathrm{~Hz}$. With Somaloy500 the $\mathrm{x}$-axis force were almost 9 times higher than the Steel1010 as primary core material.
\end{abstract}

\section{Key words}

Core Material, Numerical Model, Soft Magnetic Composite and Three-phase Planar Actuator.

\section{Introduction}

Researches present the Three-phase Planar Actuator (T.P.A.) as an traction element capable to be used in bidirectional movements executed by a single mechanism. It has a higher efficiency when compared to a common mechanical arrangements based in rotary engines, gears and shafts. These mechanical systems produce large losses of power transmission, severe wear - due to friction of the mechanical parts even when it is used with low viscosity fluids for lubrication - which increases operating costs, mainly related to maintenance. [1]

It is possible to build the T.P.A. with Soft Magnetic Composite (SMC) materials as ferrite somalloy, permalloy, and others - with high magnetic permeability provides advantages when compared to conventional materials. It is possible to manufacture machines with lower energy consumption, smaller size and higher performance. Since these composite are liable to be used in the electric planar actuator's core manufacture.

Although in purpose to optimize the development processes of materials and equipment the reduced model becomes a less expensive and easier alternative to manufacture. It minimizes the high costs associated with engineering and metal composite used in the manufacturing of prototypes to validate the simulations.

The interest observed in these materials development has been increased due to advances in metallic composite and processes related to the area of powder metallurgy aiming highest yield, efficiency and lower costs. This interest is associated with the substantial increase in linear electric machine's research - especially for industrial and transportation applications -- based on electromagnetic phenomena. The increasing interest in these devices is intimately connected to the emergence of new materials and constant modernization of control techniques dictated by more efficient dedicated systems.

In this context, this article presents comparative results of the reduced model that represents $33 \%$ of T.PA.'s size. With its the validation it is possible to evaluate the performance of the complete model with different materials used in confection of this core. 


\section{A Three-Phase Planar Actuator with two Degrees of Freedom}

The Three-phase Planar Actuator (T.P.A.) configures itself as an electromagnetic device with movement on a plane with two degrees of freedom from a single traction device. It is consisted by a car which has two independent Three-phase windings orthogonal each other - one along in the $\mathrm{x}$-axis another in the $\mathrm{y}$-axis -- constructed on a ferromagnetic core translador, and a stator formed by an aluminum plate constructed over a ferromagnetic core (see figure 1).



Fig. 1. Perspective view of the actuator and its parts

The primary element - that is the mover part - is mounted with a ferromagnetic single core constructed with 9 equal teeth. Each tooth has 2 coils referring one per different winding. The upper coils are for $\mathrm{X}$ axis translation and lower for $\mathrm{Y}$ axis movement. When supplied with three-phase sinusoidal balanced current it produces a traveling field which induces electrical current in the secondary auxiliary plate as conventional induction motors. The induced current and traveling field interaction produces linear forces in 2 perpendicular axes giving two degrees of freedom to this device.

About the materials, the primary core must be ferromagnetic with low conductivity and high magnetic permeability such as secondary core. The auxiliary plate thin, with the maximum around $1 \mathrm{~mm}$ - is purposely mounted in air gap location - between primary and secondary cores - to give a low impedance way for induced currents.

\section{Applied Materials}

The AISI1010 Steel was used to manufacture the complete and reduced core due to fabrication's ease and low cost associated with the high relative magnetic permeability. However the electrical resistivity is lower when compared to other materials used in ferromagnetic cores of electrical equipment - rolled steel, for example. Thus, the solid steel is more susceptible to the establishment of parasite electrical currents when exposed to variation of magnetic flux density. Which represents a use limitation of this material in magnetic circuits core's construction according to these eddy current losses that may represent [2] [3].

In the simulations was used Somaloy500, due to soft ferromagnetic properties of the composite applied in low frequencies devices in the order of up to $400 \mathrm{~Hz}$ by presenting low total magnetic losses in this range. The material is composed of metal powders, binders and lubricants. The addition amount of lubricant and/or binder to the metallic powder in the compaction and thermal treatment determine magnetic, electrical and mechanical properties of the final product [4] [5].

The material produced by powder metallurgy has a sintering phase, which limits the relative magnetic permeability and, due to the addition of binder, the material a high electrical resistivity. These characteristics can be interesting in some magnetic applications, where the induced currents present losses to the device being classified as Foucault current.

The magnetization curves, analyzed in material properties data, that relate the magnetic flux density (B) and the magnetic field $(\mathrm{H})$ are important to define the material's operation point, the material's saturation value and its magnetic permeability.

In regard to the material's maximum relative magnetic permeability the Somaloy 500 with $0,5 \%$ of Kenolube $500^{\circ} \mathrm{C}$ for $30 \mathrm{~min}$. in the air - has a maximum relative permeability of 500 and coercive field of $250 \mathrm{~A} / \mathrm{m}$.

\section{Experiment}

A real T.P.A. was built for experiments and many other studies. Meanwhile the complete version core is a complex model for machining and it turns expensive to make different materials versions for $R \& D$. The reduced model was also produced and its reduced dimensions facilitates to explore many possibilities and new materials configurations. The real measurements were made in each core's version - complete and reduced - mounted with copper coils and over a secondary disposed same as the original project (figure 2).

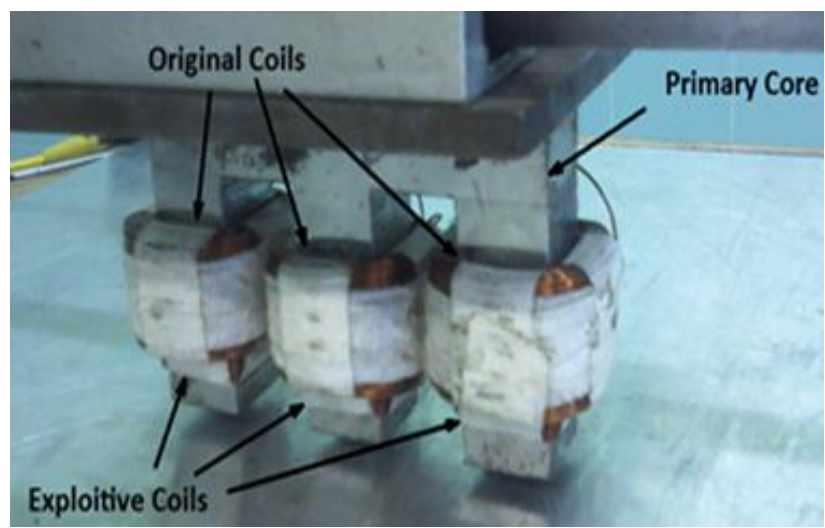

Fig. 2. Real Reduced Model.

The figure 3 presents complete model which when the 2 coils per teeth are mounted, there is no enough space for exploratory coils. Thus, new windings were made and substituted in selected teeth to put the exploratory coil together. The new windings have the same 250 turns as the original coils but with thinner wire. 


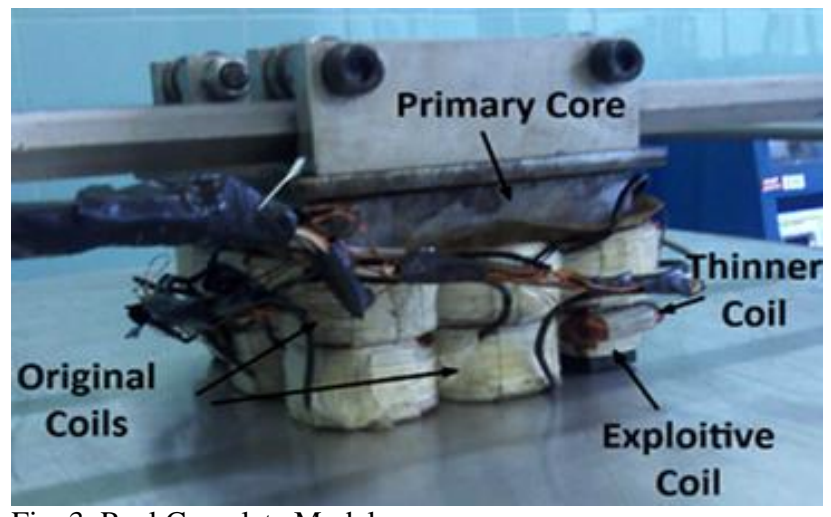

Fig. 3. Real Complete Model.

\section{The Physical Models' Numerical Analysis}

The model inserted into the finite element software is compound by primary formed from a single block with electrical isolation between it and the coils. The windings - each with 250 spirals - are disposed by one unit for tooth. The superior coils were originally made for displacement in $\mathrm{x}$-axis. The lower coils - originally projected for $\mathrm{y}$-axis movement - were substituted by exploratory coils. These alterations result in two different winding in each tooth. The exploratory coils have 50 spirals of thinner wire. They were feed with balanced three-phase sinusoidal alternating current. This device has only one degree of freedom and it is based in the same functioning principle of complete model.

For simulations, the completed and reduced model was inserted in finite-element method software with all relevant characteristics as shown in figures 4 and 5 .

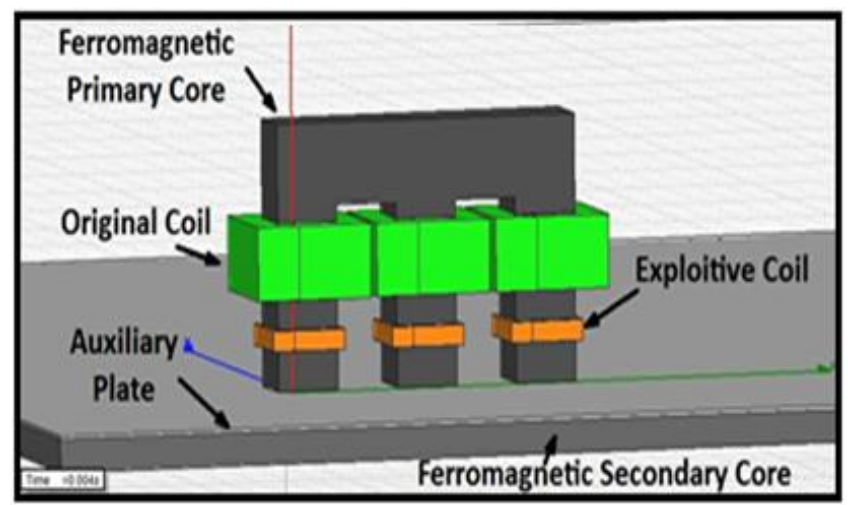

Fig. 4. Inserted reduced model in simulation software.

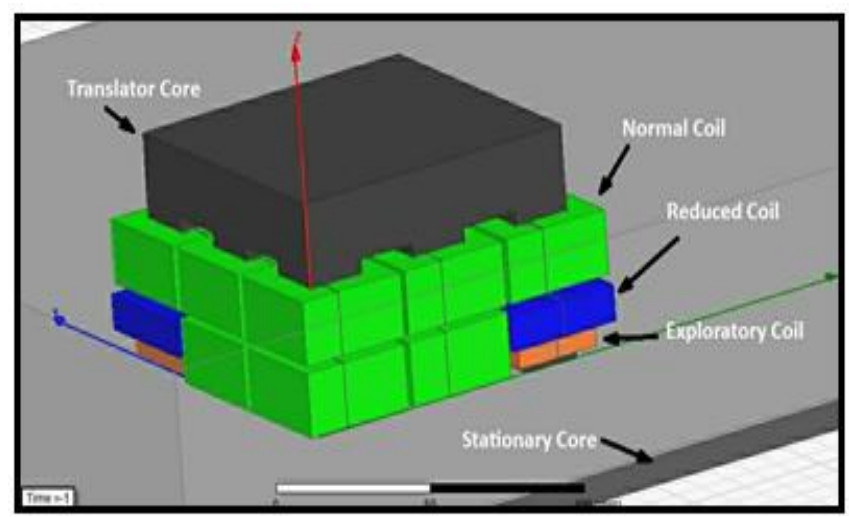

Fig. 5. Inserted completed model in simulation software.

To the devices power supply the original coils were fed by three-phase current with Y-mode of coils connection.
The exploratory coils were short-circuited and virtual ammeters were connected in each one. Figure 6 shows how it was made. The main coils resistance was irrelevant because of its current measuring. To the exploratory, however, it was inserted in software to extract correct results of induced current.
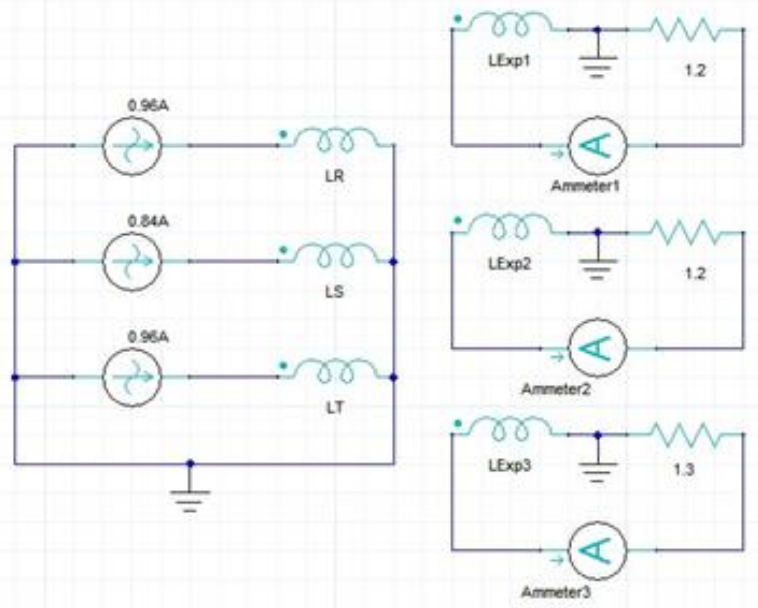

Fig. 6. Feeding schematic circuit for reduced model.

Where: LR, LS, and LT were the upper coils for R, S and $\mathrm{T}$ phases respectively and LExp1, LExp2, and LExp3 were the exploratory coils. In all simulations the current was set by real previous measurements.

The setup configuration of the simulations was established according to operating frequency to give responses for 2 complete cycles of the first phase. The results were obtained by graph mode - as seen on figure 7 - and the calculated mean was used for its discussion.

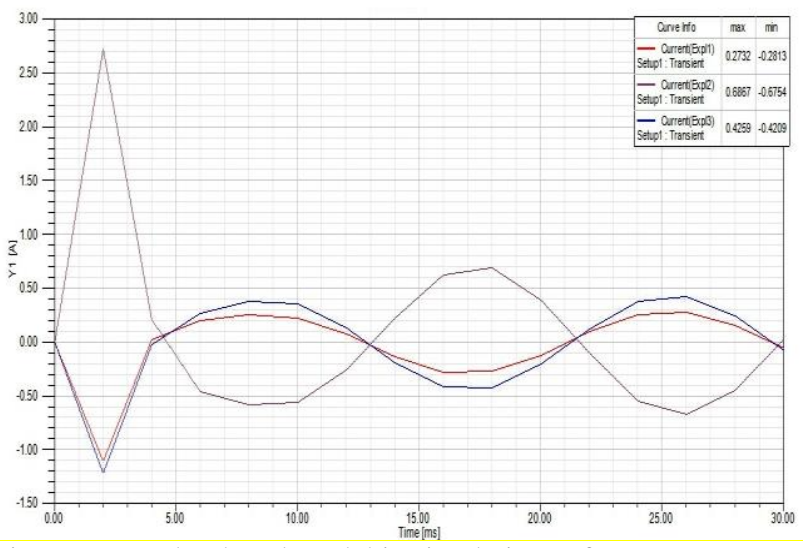

Fig. 7. Inserted reduced model in simulation software

\section{Results Analysis}

As seen on tables 1 and 2 the computational model is consistent with real model. The second part of this study seeks to obtain performance indicatives by changing the primary core material from Steel1010 to SMC Somaloy500. Thus, new simulations were made just changing the material at assembly and frequency operation setting. The table 3 shows obtained values with these new simulations based in previous adjusted - and validated - model where it is possible to compare the device's performance with Steel1010 and SMC Somaloy500. 
Table 1 - Comparative between real and simulated complete core

\begin{tabular}{|l|l|l|l|l|}
\hline \multicolumn{5}{|l|}{ Force Simulation (Material Comparative) } \\
\hline Frequency [Hz] & $\begin{array}{l}\text { Input } \\
\text { Current [A] }\end{array}$ & $\begin{array}{l}\text { Primary } \\
\text { Material }\end{array}$ & Force [N] & Gain [\%] \\
\hline 30 & 3 & Steel1010 & 5,5863 & $0,00 \%$ \\
\hline 30 & 3 & Somaloy & 15,7924 & $282,70 \%$ \\
\hline 60 & 3 & Steel1010 & 3,58 & $0,00 \%$ \\
\hline 60 & 3 & Somaloy & 14,8367 & $414,43 \%$ \\
\hline 90 & 3 & Steel1010 & 2,9305 & $0,00 \%$ \\
\hline 90 & 3 & Somaloy & 14,5987 & $498,16 \%$ \\
\hline 120 & 3 & Steel1010 & 1,4911 & $0,00 \%$ \\
\hline 120 & 3 & Somaloy & 13,3267 & $893,75 \%$ \\
\hline
\end{tabular}

Table 2 - Comparative between real and simulated reduced core

\begin{tabular}{|c|c|c|c|c|}
\hline \multicolumn{5}{|c|}{ Complete Model } \\
\hline Phase & $\begin{array}{l}\text { Input Current } \\
\text { [A] }\end{array}$ & $\begin{array}{l}\text { Real Output } \\
{[\mathrm{A}]}\end{array}$ & $\begin{array}{l}\text { Sim. Output } \\
{[\mathrm{A}]}\end{array}$ & \begin{tabular}{|l} 
Error \\
{$[\%]$}
\end{tabular} \\
\hline \multicolumn{5}{|c|}{ Setpoint $=0.5 \mathrm{~A}$} \\
\hline R1 & 1,43 & \multicolumn{2}{|l|}{$\operatorname{Exp} 1$} & \multirow[b]{2}{*}{8,12} \\
\hline S1 & 0,99 & 0,49 & 0,5298 & \\
\hline T1 & 1,26 & \multicolumn{2}{|l|}{$\operatorname{Exp} 2$} & \multirow[b]{2}{*}{7,58} \\
\hline R2 & 1,27 & 1,19 & 1,0998 & \\
\hline \begin{tabular}{|l|} 
S2 \\
\end{tabular} & 1,05 & \multicolumn{2}{|l|}{$\operatorname{Exp} 3$} & \multirow[b]{2}{*}{1,95} \\
\hline $\mathrm{T} 2$ & 1,18 & 0,8 & 0,7844 & \\
\hline \multicolumn{5}{|c|}{ Setpoint $=0.1 \mathrm{~A}$} \\
\hline \begin{tabular}{|l|} 
R1 \\
\end{tabular} & 0,76 & \multicolumn{2}{|l|}{ Exp 1} & \multirow[b]{2}{*}{0,46} \\
\hline S1 & 0,51 & 0,28 & 0,2813 & \\
\hline \begin{tabular}{|l|}
$\mathrm{T} 1$ \\
\end{tabular} & 0,65 & \multicolumn{2}{|l|}{$\operatorname{Exp} 2$} & \multirow[b]{2}{*}{9,64} \\
\hline \begin{tabular}{|l|} 
R2 \\
\end{tabular} & 0,68 & 0,76 & 0,6867 & \\
\hline \begin{tabular}{|l|} 
S2 \\
\end{tabular} & 0,54 & \multicolumn{2}{|l|}{$\operatorname{Exp} 3$} & \multirow[b]{2}{*}{9,38} \\
\hline $\mathrm{T} 2$ & 0,62 & 0,47 & 0,4259 & \\
\hline
\end{tabular}

Table 3 - Comparative between materials applied in the complete core simulated

\begin{tabular}{|c|c|c|c|c|}
\hline \multicolumn{5}{|c|}{ Reduced Model } \\
\hline Phase & Input Current $[\mathrm{A}]$ & Real Output $[\mathrm{A}]$ & Sim. Output $[A]$ & $\begin{array}{l}\text { Error } \\
{[\%]}\end{array}$ \\
\hline \multicolumn{5}{|c|}{ Setpoint $=1 \mathrm{~A}$} \\
\hline $\mathrm{R}$ & 0,96 & 0,77 & 0,7806 & 1,38 \\
\hline $\mathrm{S}$ & 0,84 & 0,91 & 0,8846 & 2,79 \\
\hline $\mathrm{T}$ & 0,96 & 0,73 & 0,7451 & 2,07 \\
\hline \multicolumn{5}{|c|}{ Setpoint $=2 \mathrm{~A}$} \\
\hline $\mathrm{R}$ & 3,15 & 1,87 & 1,9627 & 4,96 \\
\hline $\mathrm{S}$ & 2,03 & 1,81 & 1,8176 & 0,42 \\
\hline $\mathrm{T}$ & 2,11 & 1,72 & 1,6035 & 6,77 \\
\hline
\end{tabular}

To these simulations, the feeding current was set in $3 \mathrm{~A}$. It represents the same energy consumption from source. The response was measured in linear force of planar propulsion to $\mathrm{X}$ axis. In all cases SMC presents a better response and it gets higher when the frequency increases. At $120 \mathrm{~Hz}$ the force is almost 9 times higher with Somaloy500 than Steel1010 as core material.

\section{Conclusion}

It is undisputed the importance of simulations in $R \& D$ of new electromagnetic devices. However, previous validations become fundamental to the expected reliability of results obtained from simulations.

The biggest error obtained in this study did not exceed $9.64 \%$ - it represents a difference of $0.073 \mathrm{~A}$ - which is a small enough margin to the complexity of a simulation of electromagnetic devices.

With the assurance of the simulated model's validation the analysis' results with different cores have important credibility to the decision-making in TPA researches. The SMC Somaloy500 showed a much higher performance than the Steel1010 particularly at high frequencies.

The T.P.A. as machine development has been the target of this study, however, other equipment might be revalued using the same methodology. This analysis - full of rich detail - would not be possible without the use of modern tools available nowadays.

\section{References}

[1] BAGGIO FILHO, Nolvi Francisco; FLORES FILHO, Aly Ferreira. An Analysis on Electric and Magnetic Behaviour on an Induction Planar Actuator. Journal Of Microwaves, Optoelectronics And Electromagnetic Applications, Brazil, v. 12, n. 1, p.37-48, jun. 2012

[2] ESSWEIN JUNIOR, Jorge Alberto Lewis. Desenvolvimento de Compositos Magnéticos Macios Utilizados em Núcleos de Máquinas Elétricas. 2009. 117f. Dissertação - Departamento de Pós-graduação em Engenhara de Minas, Metalúrgica e de Materiais - PPGEM. Universidade Estadual de Campinas. Porto Alegre. 2009.

[3]FLORES FILHO, Aly F.; BAGGIO FILHO, Nolvi F.. Analysis of an Induction Planar Actuator. XIX International Conference On Electrical Machines, Rome, p.978-984, 2010.

[4]FLORES FILHO, A. F.; SUZIM, A. A.; SILVEIRA, M. A. Produção de Movimento Bidirecional Através de um Novo Atuador Planar. In: SEMINÁRIO NACIONAL DECONTROLE E AUTOMAÇÃO - SNCA, 2001, Salvador. Anais... Salvador: AINST/IEEE /UFBA, 2001. TT-041.

[5]FLORES FILHO, A. F.; SUZIM, A. A.; SILVEIRA, M. A. 3D Analisys and Simulation of a Novel Planar Actuator. In: INTERNATIONAL CONFERENCE ON ELECTRICAL MACHINES, 2000, Espoo. Proceedings... Espoo: Helsinki University of Technology, 2000.v.3, p. 1379-1383.

[6]SHOKROLLAHI, H. \& JANGHORBAN, K. 2007. Soft magnetic composite materials Journal of Materials Processing Technology, London (UK), Vol. 189,1-12 ( Classificação SMC) 